\title{
7 INTERNET VOTING: A Conceptual Challenge to Democracy
}

\author{
Wolter Pieters \\ Radboud University Nijmegen \\ Nijmegen, The Netherlands
}

\begin{abstract}
In this paper, we discuss the implications for social inclusion of the advent of Internet voting. Although the issue of social exclusion or social inclusion with regard to technological developments in the voting process is often approached as a matter of either security or turnout, we will take a broader view. Using the philosophical concept of technological mediation, as developed by Don Ihde and Peter-Paul Verbeek, we claim that Internet voting may change our experience of democracy, and transform the way we act as citizens in the democratic system. We argue that the mediating role of voting technology requires reconstruction of concepts used in discussing democracy. Our approach of reconstruction departs from the political philosophy of John Dewey. Based on his work, we can describe the political process in a democracy in terms of intellectual reconstruction and institutional reconstruction. Combining the concept of technological mediation and Dewey's political philosophy, we use the mediating role of online voting technology as input to the intellectual reconstruction of the discussion on voting and democracy. Based on the developments in the Netherlands, we present some challenges that the mediating role of online voting technology offers to existing concepts in democracy, and evaluate the benefits for social inclusion of reconstructing these concepts with respect to the new possibilities.
\end{abstract}

\section{INTRODUCTION}

Throughout history, philosophers as well as citizens have often lamented the status of democracy. While John Dewey complained about the "eclipse of the public" in 1927, the Dutch said there was a feeling of onbehagen or discomfort concerning politics in the period of the rise and fall of the populist party of Pim Fortuyn in 2002. The "diseases"

Please use the following format when citing this chapter:

Pieters, W., 2006, in IFIP International Federation for Information Processing, Volume 208, Social Inclusion: Societal and Organizational Implications for Information Systems, eds. Trauth, E., Howcroft, D., Butler, T., Fitzgerald, B., DeGross, J., (Boston: Springer), pp. 89-103. 
that are diagnosed are often considered a threat to social inclusion ${ }^{1}$ in terms of participation in the democratic process. If people are alienated from politics, it is said, representative democracies cannot function properly. Many cures to these alleged diseases have been proposed. Meanwhile, new democracies are being established in countries with different levels of development all over the world.

Since the early 1990s, however, democracy has been changed by something other than political and social developments. The rise of the information and network society, and the accompanying technologies, did not leave democracy untouched. This is especially true in elections. Although mechanical voting machines have been in use for a long time, the impact of the information and network society on the voting process is and will be far more profound. The introduction of electronic voting machines has already shown this. ${ }^{2}$

Today, we are looking ahead to the option of online voting. ${ }^{3}$ People tend to do more and more of their transactions online, and the mere existence of these other technologies makes them sensitive to the trouble that casting a vote still brings, in the act of going to the polling station. In the Netherlands, two Internet surveys showed that, depending on the context of the question, between 62 and 79 percent of the Dutch citizens using the Internet would like to vote online. ${ }^{4}$ Meanwhile, relatively new democracies such as Estonia are eager to become the early adopters of such modern forms of voting (Dreschler 2003; National Election Committee 2004).

Of course, the issue whether it is desirable to make voting easier for certain groups of people, namely those who have Internet access at home or at work, is a topic of discussion from the point of view of social inclusion itself, in terms of turnout among different groups (Alvarez and Hall 2004, Chapter 3). In developing countries, an infrastructure of physical, digital, human, and social resources is needed to be able to provide online democracy at all (Warschauer 2004, p. 47). Also, many people have pointed out security threats to online voting systems, or electronic voting systems in general, that may be a threat to social inclusion, especially hacking and manipulation by insiders (Jefferson et al. 2004; Kohno et al. 2004; Phillips and Von Spakovsky 2001; Weinstein 2000).

In this paper, however, we focus on the role of online voting technology in people's experience of democracy. Even if Internet voting can be implemented in a secure way based on technical, organizational, and legal measures, and even if we do not consider

\footnotetext{
'Warschauer (2004) defines social inclusion as "the extent that individuals, families and communities are able to fully participate in society and control their own destinies, taking into account a variety of factors related to economic resources, employment, health, education, housing, recreation, culture and civic engagement" (p. 8, emphasis added).

${ }^{2}$ See the Commission on Electronic Voting (www.cev.ie) and Kohno et al 2004. We will not discuss electronic voting machines and the associated security issues in this paper.

${ }^{3}$ In this paper, we will use the terms "Internet voting" and "online voting" synonymously, in the sense of remote Internet voting (from any computer connected to the Internet). We do not discuss other forms of Internet voting that use access restrictions (Alvarez and Hall 2004, p. 4).

${ }^{4}$ Burger@overheid publiekspanel: stemmen via internet (Citizen@government public's panel: Voting via Internet), www.burger.overheid.nl/publiekspanel/?id $=25$, November 1, 2004, and www.burger.overheid.nl/publiekspanel/?id=628, September 23, 2004 (in Dutch).
} 
the possible shift in turnout among different groups a problem, there are still many aspects in which it may have unexpected effects. The role of technology in changes in societal life has been shown in many other cases, and voting will not be an exception. This is not to say that technology is autonomous (see Winner 1977) and we follow blindly. But technology is not neutral either, and if we do not take the issue into account, it will be an implicit force in future decisions on voting and democracy.

Democracy is not a static system, and many different theories about its form and function exist (See Cunningham 2002; Held 1997). The discussion on the supposed problems of current democratic institutions cannot be intelligently conducted without knowledge of the impact of new voting technology, especially Internet voting, on the democratic process. An attempt to include technology in the debate is necessary to prevent technology from changing democracy without well-founded political discussion, which would be a serious case of social exclusion in its own right (for a discussion of similar issues, see Harbers 1996). Although voting technologies do receive increased attention in the scientific community, a general framework that can be used in connecting scientific and political discourses is needed. We aim at providing such a framework in this paper.

This paper is organized as follows. First, we discuss our methodology for including technology in the debate on the future of democracy, which is based on the political philosophy of John Dewey and the postphenomenological approach in philosophy of technology. Then, we introduce the possibilities of online voting via a description of the situation in the Netherlands. In section 4, "Challenges to Democracy," we present some results of our methodology by identifying challenges that Internet voting brings to democracy, based on the situation in the Netherlands. These results can be extended by applying our methodology to other cases. In the final section, we present our conclusions and recommendations.

Our conclusions regarding the methodology we develop in this paper do not depend on our choice for the Netherlands as a setting. However, we certainly do not claim completeness of the list of challenges to democracy that is presented, and more (possibly comparative) case studies may yield additional results. Interesting developments to study are found in the United Kingdom (BBC News 2003), the United States (Jefferson et al. 2004), Switzerland, ${ }^{5}$ and Estonia (Drechsler 2003; National Election Committee 2004).

\section{THE ROLE OF TECHNOLOGY IN DEMOCRACY}

In this section, we present the philosophical theories we use in our attempt to include voting technology in the discussion on voting and democracy. Our methodological view is based on the philosophy of John Dewey, whose views on ethics and democracy have been excellently investigated in the Dutch work by Louis Logister (2004). According to Dewey, institutional changes in a democracy are achieved by a process of reconstruction. We describe the role of technology in this reconstruction in

${ }^{5}$ Official l'Etat de Genève Web page, "E-voting," http://www. geneve.ch/evoting. 
terms of mediation, a concept developed by the postphenomenological approach of Don Ihde (1990) and Peter-Paul Verbeek (2005).

\subsection{John Dewey's Notion of Democracy}

John Dewey is a well-known philosopher from the United States, who considers himself an instrumentalist. A more widely known term for the movement that he belongs to is pragmatism. In this section, we will briefly introduce his views on the role of reconstruction in democracy. We cannot cover his theory in depth here, but we will provide references for further reading.

Dewey considers everything, including theories, norms, and values, as tools that function in the context of experience, where experience means continuous interaction between a human being and her environment. "To Dewey, experience is not a mental storage place for empirical sensations, as proposed by traditional correspondence theories, but a complex integrated activity that is characterized by goal-directedness, prospectivism and growth of meaning" (Logister 2004, p. 76, my translation). Dewey's naturalist concept of experience necessarily contains something active and something passive, trying and perceiving.

In the context of experience, Dewey frequently uses the concept of habit. This is an acquired tendency to act in a certain way in certain situations (Logister 2004, p. 91, referring to Dewey's Human Nature and Conduct). Since they are acquired, habits are socially transmitted. If a habit is common within a certain society, this common mode of action is called a custom. Habits are reflected in the institutions in a society. The most efficient way to change habits is by starting to change the institutions.

Based on these points of departure, Dewey develops his ethical and political theories. Dewey's ethics refrains from posing specific goals, and states that "growth itself is the only moral "end"' (1948, p. 175) By growth, he means increasing ability to solve problems that hinder the continuous stream of experience. Politics concerns decisions on how to rearrange institutions such that growth in society becomes possible. The best way to do this is a democratic one, since it provides the best capacity for mobilizing the existing problem-solving resources in a society, especially if it is arranged in a participative way (not only votes, but also direct input from the people in political discussion). "Democracy is a name for a life of free and enriching communion... It will have its consummation when free social inquiry is indissolubly wedded to the art of full and moving communication" (Dewey 1991, p. 184).

Logister (2004) argues that the idea of social reconstruction (i.e., the reconstruction of the institutions in a society in order to enable growth) is at the heart of Dewey's political philosophy. He refers to the work of James Campbell (1995) in order to further clarify the idea of social reconstruction, which remains rather implicit in Dewey's own work (Logister 2004, pp. 220-226). Following Campbell, he distinguishes two aspects of Dewey's social reconstruction: intellectual reconstruction and institutional reconstruction. In democracy, intellectual reconstruction precedes institutional reconstruction. Intellectual reconstruction consists of formulating the problems that a society faces, and suggesting solutions to these problems. An important part of this task is the reconstruction of the conceptual meaning of political terms. Institutional reconstruction 
means evaluating the proposed concepts and solutions, and adapting existing institutions based on this evaluation. Whereas institutional reconstruction requires political discussion and should be based on democratic decisions, intellectual reconstruction is the task of philosophers and scientists.

Dewey's ideas on the role of experience and habits in society thus lead to a particular vision on how society can and should be changed. Science does the intellectual reconstruction, politics does the institutional reconstruction. We think that this separation of concerns can be fruitful for both. Moreover, the concept of intellectual reconstruction itself, as provided by Campbell and Logister based on Dewey's work, can serve as the basis for a particular way of analyzing technological developments in society, namely in relation to the reconstruction of our conceptual framework.

\subsection{Technological Mediation}

How can we understand the challenges that technological developments bring to our conceptual framework, for example the mobile phone? The mobile phone is not just a neutral means of solving a communication problem. Although it is effective with regard to its purpose, communication at non-fixed places and during travel, it has also completely changed the way in which people experience each other's presence and the way in which people arrange their schedules and meetings. "I'll call you when the train leaves the station; pick me up half an hour later." This also requires people to be reachable by mobile phone. The few people who don't have one by now may even run the risk of becoming socially excluded.

Several philosophers have described such developments from what is called the empirical turn in philosophy of technology (Achterhuis 2001). Whereas traditional philosophy of technology had often analyzed "technology" as a phenomenon in itself, these movements argue that we should analyze the role of concrete technological artifacts in our lives in order to understand what technology is all about. These approaches have been inspired by empirical studies into such developments.

One theory on the role of technology in our experience of our world and in the way in which we realize our existence has been described based on notions of the philosophical movement of phenomenology. Especially intentionality, the directedness of people toward their environment, has been used as a concept in describing changes in the lifeworld invoked by technological developments. It is said that technology can mediate our relation to our world by forcing itself into the intentional relation. Thereby, it may amplify as well as reduce certain aspects of our experience.

The work by Ihde (1990) focuses on these forms of mediation. In the mobile phone example, we can state that this technology amplifies the interpretation of known people as directly available for contact, whereas the presence of people we do not know in our direct environment (e.g., in a train) is reduced. Verbeek (2005) takes one step further in the theory of mediation, and states that technology can not only change our experience, but also the way in which we act, by invitation and inhibition of certain actions. A mobile phone invites calling people when it is not strictly necessary ("I caught the train I said I would catch"), and this may even become a social norm. At the same time, it inhibits talking to people in the train. 
In the same sense, Internet voting is not only a means to make it easier to vote. It can profoundly change the relation between people and their environment, in this case the political world of democracy. Interpretations of what democracy is can be shifted, and Internet voting will invite different voting behavior. We therefore think that the phenomenological approach can be a fruitful starting point for a description of the possible changes that Internet voting brings to democracy, which can then serve as a basis for an intellectual reconstruction of the concept of voting in the network age.

\subsection{Our Approach}

Pragmatism is an especially helpful philosophical approach in cases where the conceptual framework is not fixed. Because of the mediating role of technology, introduction of new technologies is precisely such an issue. In this paper, we perform the intellectual reconstruction of the concept of voting based on the technological developments in the information society. We investigate the mediating role of voting technology in society, and reconstruct the discussion on voting and democracy based on the challenges that technology brings. Thus, our approach applies the theory of mediation of human experience and existence by technology, not only after the fact, but as an input to the political discussions that will guide the introduction of the new technology. This can be seen as a special approach to constructive technology assessment (Schot and Rip 1997).

\section{INTERNET VOTING IN ACTION}

We will introduce the application of our methodology to online voting by describing the developments around online voting in the Netherlands. Next to the fact that we are most familiar with the Dutch situation, we think that the Netherlands provide an interesting case study for the following reasons. First, the Netherlands were one of the first countries to introduce electronic voting machines on a large scale, which yields an interesting setting for online developments. Second, the Dutch Ministry of Domestic Affairs is very open about the development of new technologies, and cooperates intensively with the scientific community. Third, the typical Dutch phenomenon of local water management authorities (waterschappen) offers a particularly fruitful niche for online voting to develop (Weber et al. 1999).

In the Netherlands, several experiments have been performed with voting via the Internet. During the European elections in 2004, Dutch citizens living abroad were allowed to vote online. Moreover, elections for two local water management authorities combined postal ballots with Internet voting in the fall of 2004 , with a total of 120,000 actual online voters. Although one of the main reasons to start such experiments, increasing turnout, does not seem to be based on empirical evidence, ${ }^{6}$ people either tend

${ }^{6}$ See Oostveen and Van den Besselaar (2004). Also, the first elections using the RIES system, to be discussed later, showed decreased turnout. 
to be enthusiastic about it for other reasons, or argue that turnout will be increased when Internet voting is used in more appealing elections.

The first of the two experiments in the Netherlands was initiated by the Ministry of Domestic Affairs. They decided that citizens living abroad, who could already vote by postal ballot, should be given the opportunity to vote via Internet or phone. For this purpose, the KOA system was developed, ${ }^{7}$ and a law regulating the experiment was passed through parliament. The experiment took place during the European elections in 2004. A follow-up trial is planned for the national elections in 2007.

A more sophisticated system was developed with far less money by the local water management authorities of Rijnland ${ }^{8}$ together with two companies cooperating under the name TTPI. ${ }^{9}$ This system, called RIES, uses cryptographic operations to protect votes and at the same time offers good transparency. It is possible for voters to verify their vote after the elections, and for independent institutions to do a full recount of the results. The Radboud University Nijmegen did such a recount, and confirmed the official result. ${ }^{10}$

Because the water management authorities are not bound by Dutch election law, they are relatively free in their means of voting. In 2008, all local water management authorities will use the RIES system in their combined elections. We expect that RIES or similar systems will find their way into more official elections at local level soon. ${ }^{11}$ This makes the issue of incorporating technological developments in discussions on democracy pressing.

We present some challenges that Internet voting brings to the discussion on voting and democracy next. We use features of the Dutch RIES system to illustrate our points.

\section{CHALLENGES TO DEMOCRACY}

The advent of Internet voting is not just a matter of changing the means of attaining certain ends. By introducing new technologies, the relation between people and their environment can be changed, in terms of experience and action. In this section, we try to intellectually reconstruct the concept of voting, based on the challenges that the mediating role of Internet voting offers to traditional conceptions of and discussions on democracy. These issues can serve as a starting point for the institutional reconstruction that Internet voting requires. We do not strive for completeness here, but we show the most important issues we identified based on our knowledge of and experience with

${ }^{7}$ Ministerie van Binnenlandse Zaken en Koninkrijksrelaties (2004), see also www.minbzk.n1/grondwet_en/kiezen_op_afstand (Remote Voting) (in Dutch).

${ }^{8}$ Hoogheemraadschap van Rijnland (Public Water Management Authorities of Rijnland) (www.rijnland.net and www.rijnlandkiest.nl, in Dutch).

${ }^{9}$ TTP Internetstemmen (TTPI Internet Voting) (www.ttpi.nl, in Dutch).

${ }^{10}$ More information about RIES is available in Hubbers et al. (2005).

${ }^{11}$ The Beverwijk local authorities announced that they wished to use a new system in the 2006 local elections (www.beverwijk.nl/websites/beverwijk/website/default.asp? Path $=1731$, in Dutch). However, the Ministry did not approve their proposal, officially because the law could not be adapted in time. 
online voting systems in the Netherlands. Neither do we take an exclusively positive or negative point of view here. The challenges that we identify can work out either way, depending on how we handle them.

\subsection{A Challenge to Individual Rational Choice}

In common sense, democracy means one man, one vote. People are assumed to make their choices individually, based on rational deliberation. This is an individualistic vision, related to the common economic conceptions of individual desires and choices. ${ }^{12}$ However, psychological research has indicated that people are not as individual as Enlightenment philosophers might first have thought. Dewey already noticed this, and his concept of habits can be thought of as a way to criticize individualistic theories.

Dewey indicates that by the implicit assumptions of liberalism and individualism, people are assumed to be free, whereas they are at the same time unconsciously suppressed by the very values of these "isms." By stressing too much the individual capacities as opposed to social structures, traditional social ties fall apart and people become easy prey for manipulation, such as by mass media. The irony is that by focusing too much on the freedom of the individual, freedom and political discussion seem to be inhibited.

The continuation of the process of individualization in the last century also has implications for elections. Whereas people tended to vote for the party connected to the social group they belonged to before, they are now free to vote how they want. At the same time, it becomes more interesting to persuade voters. This is one of the reasons why elections tend to become more and more of a media circus.

Although many alternative visions on democracy are readily available in (scientific) literature, existing institutions and technologies play an important role in maintaining the status quo. Using current election systems, it is hard to think of a different way of collecting votes that would introduce a less individualistic conception of voting and more consciousness of the alternatives that are available to the view that the media offer. In the online case, however, things may have a more flexible nature.

First of all, it becomes more interesting to use different methods of tallying, like weighted voting, where one can mark more than one candidate in a chosen order. Whereas the design of paper ballots or dedicated voting machines does not offer much flexibility, ${ }^{13}$ voting via a web site allows for all the flexibility that is needed to implement different voting schemes. ${ }^{14}$ A user can be taken through different screens,

\footnotetext{
${ }^{12}$ Dewey (1991, p. 86). Dewey further states, "The utilitarian economic theory was such an important factor in developing the theory, as distinct from the practice, of democratic government that it is worth while to expound it in outline" (p. 91)

${ }^{13}$ Many people remember the Florida "butterfly ballots" in the 2000 U.S. presidential election. Due to bad design, many people are suspected to have chosen the wrong candidate. If designing ballots for the one man, one vote system is already hard, there is no way of integrating different methods of tallying into the old-fashioned election system.

${ }^{14}$ This is also true for non-remote forms of Internet voting, where people cast their vote on a protected $\mathrm{PC}$ located in a polling station, for example.
} 
where confirmation can be asked at each point, and-by consistency checkingovervoting or undervoting can be reduced to practically zero, even in case of complicated ballots (see Alvarez and Hall 2004, p. 40). This makes it quite relevant to discuss the benefits of different voting schemes again, and this can be fruitful for our consciousness of alternatives in the democratic process, since we may be allowed to select more than one candidate. When it becomes possible to cast more than one vote, some of the rational benefit analysis is challenged, since it is no longer required to weigh, for example, national nature preservation against foreign policy in the choice for one party. One can choose both by casting two votes. The concept of voting is subject to reconstruction here.

An even more interesting feature of the RIES system is that it is impossible ${ }^{15}$ to create valid votes without the appropriate access token (e.g., a password or a chipcard). In our current election system, votes are created and collected in a safe place, and never leave the safe environment until they get counted. If creating false votes is impossible, this is not necessary anymore. Anyone may collect votes for her own purpose, and send them to the central counting facility later. For example, political parties may get the opportunity to collect their own votes. Also, interest groups may allow citizens who visit their site to cast a vote for the candidate that the interest group prefers (see Alvarez and Hall 2004, p. 59). One can then give a vote to an organization for which one feels sympathy, or that one trusts, instead of weighing party views on different issues. The experience of the group character of politics is amplified here, and the individual "rational" aspects are reduced.

Whether this is desirable should be subject to political discussion. People may be more conscious of the alternative options that they have in their participation in democracy. This would be a good thing for social inclusion in terms of the amount of choices available to voters and in the reduced distance between them and the organization to which they give their vote. On the other hand, this may lead to the advent of so-called "one-issue" parties. For example, a nature protection organization may collect votes for a political party or candidate that mainly focuses on nature, and does not have a clear opinion on immigration policy.

These options must be considered, however, since the advent of Internet voting makes them feasible, and may mediate people's experience in such a way that these possibilities are amplified in their interpretation of voting. In the same sense in which the mobile phone morphed itself from a seemingly purely instrumental business device into a social device with extensive implications for the way in which people stay in touch, Internet voting may lead to profound changes in voting practices. By mediating the practice of voting, Internet elections may raise the public's sensitivity to different voting methods. Although people cannot decide themselves how to vote, understanding of the possibilities may increase pressure on the government, and may in the long run change the entire system.

15“Impossible" here means computationally infeasible. Although this is not an absolute guarantee, the probability of being able to guess the correct values in bounded time is negligible. 


\subsection{A Challenge to the Secret Ballot}

Because Internet voting does not allow for government control over the voting environment, guaranteeing secrecy of the ballot is impossible (Jefferson et al. 2004). People can always watch over your shoulder if you cast your vote at home. ${ }^{16}$ In this sense, accepting Internet voting as the technology for casting votes will change the election system. Moreover, the mediating role of the technology will change the experience of voting, and will reduce the aspect of secrecy in the experience of the voter. If people vote at home, they may be more inclined to accept that their vote is not secret. This means that the introduction of Internet voting may lead to a whole new idea about secrecy in elections. Why is this a challenge?

The secret ballot can be important for two reasons: as instrumental to the prevention of vote buying and coercion and as an intrinsic value in democracy. In the first case, it relates to social inclusion in the sense that nobody loses her vote by either being forced or selling it. In the second case, it is related to the view that nobody needs to justify her choice in an election. We discuss both reasons in relation to the loss of secrecy in the case of remote voting.

Forced voting is already possible on a small scale in the current Dutch system, since there are limited possibilities for authorizing others to vote for you. ${ }^{17}$ One can force someone else to sign such an authorization. ${ }^{18}$ For the same reason, there is already limited opportunity for vote buying and selling. The question is what will happen if these limits on the "vote market" are abandoned. Measures should be taken to regulate this market, such that the actual number of illegal transactions remains low. If manipulation is reported anyway, secret elections may be the only remedy, but experiments need to tell if people even try. Possible measures include

- allowing voters to vote more than once, but only for different parties; this reduces the chance of one party gaining absolute majority by buying votes

- using criminal law to make vote buying and selling less attractive

- creating a good infrastructure for reporting misuse (e.g., pay double the price a buyer would pay if the potential seller reports it)

- making it more difficult to transfer access tokens (e.g., biometric authentication instead of passwords)

\footnotetext{
${ }^{16}$ This is also known as "family voting." Of course, this also holds for postal ballots, which have been used in various countries to various extents (Alvarez and Hall 2004, Chapter 6). We do not discuss postal ballots further in this paper.

17"Stemmen bij volmacht" (voting by authorization) was introduced in the Netherlands in 1928. The possibilities for authorization have been restricted over time, because, especially in local elections, there had been cases of active vote gathering; currently, you are allowed to have only two authorizations (Art. L 4 Dutch Election Law).

${ }^{18}$ Interestingly, the abandonment of the obligation to vote in 1970 increased the possibilities for manipulation: one can now force someone else to stay home, without anybody noticing.
} 
Internet voting seems to force the market out into the open. Whereas small scale vote buying was possible in the old Dutch system as well (due to limited possibilities for authorization), the opportunities now become clear. This also requires thinking about measures to prevent force (stealing) and sale. In the old days, people were unconsciously "forced" to vote for the party everyone in their social group voted for. There was not much contact between different social groups. Vote secrecy was necessary to protect the nonconformists within the groups. Nowadays, social ties are much looser. Is vote secrecy still the solution? Or should everything be open? Some research suggests that vote buying may "survive the secret ballot" (Brusco et al. 2004), thus making the value of the secret ballot as an instrument to prevent vote buying debatable. In the same sense, one may wonder if the secret ballot helps against coercion. $^{19}$

When secrecy is considered an intrinsic value, different arguments apply. Not being required to justify one's choice can be helpful if one has a nonconformist opinion. Even the idea that one's vote may not be secret may lead to more conformist voting (Oostveen and Van den Besselaar 2005). Therefore, secrecy may be considered essential in order to allow people to express their "real" choice. However, secrecy may also be a source of social exclusion. Is it not true that people will have better chances of being included in the public debate if they openly present their choice? Is it not fruitful for democracy if people debate their choices in public? These questions will need renewed deliberation if we wish to implement online voting.

In the RIES system, the sacrifice of secrecy is compensated for by a new option: it is possible to verify your vote in the results after the elections. This can only be done if your vote is not completely secret, since you need some information about your vote to be able to do the verification procedure afterward. There is no guarantee that others may not obtain this information from you in some way. However, the verification procedure presents a completely new dimension of elections. People will be less inclined to tacitly accept the results. The technology invites people to be more active in the counting procedure, which may be a good thing for social inclusion in terms of participation in the election procedures, or at least a replacement for the involvement of people in election management at polling stations in current systems. Again, this feature of the specific technology used may influence people's interpretation of elections.

\subsection{A Challenge to the Relation Between Voting and Democracy}

The last challenge we identified is that Internet voting may bring to democracy a shift in the place of voting within the democratic framework. Whereas voting is done in complete isolation nowadays, it may become more related to other political activities if the Internet is used, for example via links to other websites. The fact that people vote

\footnotetext{
${ }^{19}$ Does a wife vote against the will of her husband, even if she is threatened and beaten regularly? Social science research into these issues would be useful, although we are not aware of any such work.
} 
via the Internet can "link" the voting environment in their experience to all kinds of other options for exercising influence (such as discussion forums). When I vote in a polling station, there is no link at all to my contribution to a discussion on immigration policy in a forum. When I vote at home, I might have both windows, voting and forum, open at the same time.

The technology may mediate the relation between people and democracy in such a way that the experience of different possibilities of participation is amplified, and active participation is invited, instead of isolating voting from the rest of the lifeworld by means of a polling booth. However, this is not necessarily a benefit. If voters do not have the skills to use these additional possibilities appropriately, it may increase their dependence on opinions articulated by others (e.g., in a forum). On the other hand, if voters do have the skills, it may lead to a new "e-democracy," in which social inclusion in different democratic processes becomes more common. Again, the institutional reconstruction requires political discussion.

\section{CONCLUSIONS AND RECOMMENDATIONS}

Following John Dewey, we described the political process in a democracy in terms of intellectual reconstruction and institutional reconstruction. We think that it is important to consider technological developments in the process of intellectual reconstruction, to prevent technology from becoming an unconscious force that changes our world unexpectedly by processes of mediation. In this case, we focused on the role of Internet voting in reconstructing the concepts involved in discussing elections. Based on this analysis, we argue that there is much more to social inclusion in Internet voting than turnout or security threats.

There are two types of conclusions to draw: conclusions regarding our methodology and conclusions regarding the results of this methodology in this (limited) study. We start with the methodology, which we think is fruitful for the following reasons. First, it provides a way to reflect on the mediating role of technology before it is actually introduced, analogous to constructive technology assessment. Second, it connects technological developments with developments in our conceptual framework, or cultural categories (Smits 2002a, 2002b), in a pro-active way. This approach, therefore, has the potential to explicate challenges on a conceptual level before they present themselves in the real world. We think the results of this paper regarding Internet voting illustrate the benefits.

The results of our methodology in this paper consist of three challenges that Internet voting brings to democracy, which require intellectual reconstruction of the involved concepts. These results are based on the situation in the Netherlands, and further case studies may provide additional challenges.

First, Internet voting may require reconstruction of our idea of voting as a completely individual rational choice. Internet voting may, by the extremely flexible nature of its user interface, make us more conscious of the different election systems that are possible, ranging from different tallying methods to completely new ways of transferring votes to the central counting facility (e.g., via interest groups). In all of these cases, a shift may occur in the interpretation of voting from the individual 
weighing of benefits to the collective weighing of alternatives, which may change the way in which social inclusion in democracy is understood and realized.

Second, online voting may require rethinking the concept of vote secrecy. The mediating role of the technology will change the experience of voting, and will reduce the aspect of secrecy in the traditional sense. One may argue that this concept stems from a social situation that has been changed profoundly since, and even if Internet voting cannot guarantee complete secrecy in the old meaning, this may not be a problem in our new social situation. The questions that this transition raises are how we wish to protect voters from undue influence exercised by others, and how we wish to balance the benefits of secrecy and the benefits of openness for social inclusion. There are many solutions to these problems, and the traditional idea of vote secrecy combined with voluntary party membership is just one of the options.

Third, online voting requires discussion on the relation between voting and other aspects of democracy. Voting may no longer be experienced as an act isolated from other forms of participation. For example, voters may add comments to their votes suggesting improvements to the proposals, or ideas they would like their candidate to implement. Online voting may invite people to participate in other Internet democracy issues as well, whereas polling stations do not invite anything but voting. These features can make democracy more participative, and this may diminish the gap that is felt between citizen and government.

We investigated which concepts used in discussing democracy require reconstruction from the perspective of the new technology of Internet voting. These challenges to democracy are both opportunities and risks, depending on how they are appropriated within the existing democratic system. Additional case studies may yield more challenges than the ones we identified. We hope we have broadened the discussion on social inclusion in Internet elections from security and turnout to social inclusion in technology-mediated democracy in a broad sense; that is, to the aspect of civic engagement that is a vital part of being a full member of society.

One recommendation is to incorporate this broader view into the political discussion on the future of democracy, which may lead to institutional reconstruction based on the concepts sketched here. Whereas- in the Netherlands--the focus in this discussion lies on adoption of the chosen mayor and revision of the election procedures with more focus on regional candidates, new technologies may turn out to be a more important factor in the improvement of social inclusion in democracy. If we do not take these developments seriously, we cannot steer the adoption of the technology in a proper way, which means that we will have the same situation as in the case of the introduction of voting machines: suddenly the technology is there, and nobody knows whether we really wanted it.

\section{RELATED WORK}

Although this paper deliberately avoids the term ethics, it fits within a larger debate on the role of technology assessment and technology ethics (Grunwald 1999). A solution to this problem that is also based on a pragmatist attitude has been presented by Martijntje Smits (2002a, 2002b). Ethical considerations on the use of the Internet in 
elections have been discussed by Pieters and Becker (2005). A more social science oriented approach is found in the work by Oostveen and Van den Besselaar (2004, 2005).

\section{Acknowledgments}

This work is supported by a Pionier grant from NWO, the Netherlands Organisation for Scientific Research. The author further wishes to thank (in alphabetical order) Marcel Becker, Erik Poll, and Martijn Warnier for useful comments on drafts of this paper.

\section{References}

Achterhuis, H. "Introduction: American Philosophers of Technology," in H. Achterhuis (ed.), American Philosophy of Technology: The Empirical Turn, Bloomington, IN: Indiana University Press, 2001, pp. 1-10.

Alvarez, R. M. and Hall, T. E. Point, Click \& Vote: The Future of Internet Voting, Washington, DC: Brookings Institution Press, 2004.

BBC News. "E-Voting Fails to Stir the Public," May 2, 2003 (available online at http://news.bbc.co.uk/1/hi/technology/2995493.stm).

Brusco, V., Nazareno, M., and Stokes, S. C. "Vote Buying in Argentina," Latin American Research Review (39:2), 2004, pp. 66-88.

Campbell, J. Understanding John Dewey: Nature and Cooperative Intelligence, Chicago: Open Court, 1995.

Cunningham, F. Theories of Democracy: A Critical Introduction, London: Routledge, 2002

Dewey, J. Reconstruction in Philosophy, Boston: Beacon, 1948.

Dewey, J. The Public and its Problems, Athens, OH: Swallow Press, 1991.

Drechsler, W. "The Estonian E-Voting Laws Discourse: Paradigmatic Benchmarking for Central and Eastern Europe," unpublished paper, University of Tartu, Estonia, 2003 (available online, http://unpan1.un.org/intradoc/groups/public/documents/nispacee/unpan009212.pdf).

Grunwald, A. "Technology Assessment or Ethics of Technology?," Ethical Perspectives (6:2), 1999, pp. 170-182.

Held, D. Models of Democracy, Stanford, CA: Stanford University Press, 1997.

Harbers, H. "Politiek van de technologie" (Politics of Technology), Kennis en Methode (20:3), 1996 , pp. 308-315.

Hubbers, E., Jacobs, B., and Pieters, W. "RIES: Internet Voting in Action," in R. Bilof (ed.), Proceedings of the $29^{\text {th }}$ Annual International Computer Software and Applications Conference, COMPSAC'05, Los Alamitos, CA: IEEE Computer Society Press, 2005, pp. 417-424.

Ihde, D. Technology and the Lifeworld, Bloomington, IN: Indiana University Press, 1990.

Jefferson, D., Rubin, A. D, Simons, B., and Wagner, D. "Analyzing Internet Voting Security," Communications of the ACM (47:10), 2004, pp. 59-64.

Kohno, T., Stubblefield, A., Rubin, A .D., and Wallach, D. S. “Analysis of an Electronic Voting System," in IEEE Symposium on Security and Privacy, Los Alamitos, CA: IEEE Computer Society Press, May 2004 (available online at http://www.avirubin.com/vote.pdf).

Logister, L. Creatieve democratie: John Dewey's pragmatisme als grondslag voor een democratische samenleving (Creative Democracy: John Dewey's Pragmatism as Foundation of a Democratic Society), Budel, Netherlands: DAMON, 2004.

Ministerie van Binnenlandse Zaken en Koninkrijkstelaties (Dutch Ministry of Domestic Affairs). Project Kiezen op Afstand (Project Remote Voting), report BPR2004/U79957, November $11,2004$. 
National Election Committee. "E-Voting System Overview," Tallinn, Estonia, 2005 (available online, http:/www.vvk.ee/elektr/docs/Yldkirjeldus-eng.pdf).

Oostveen, A. M., and Van den Besselaar, P. "The Effects of Voting Technologies on Voting Behavior: Issues of Trust and Social Identity," Social Science Computer Review (23:3), 2005, pp. 304-311.

Oostveen, A. M., and Van den Besselaar, P. "Internet Voting Technologies and Civic Participation: The Users' Perspective," The Public (11:1), 2004, pp. 61-78.

Phillips, D., and Von Spakovsky, H. "Gauging the Risks of Internet Elections," Communications of the ACM (44:1), 2001, pp. 72-85.

Pieters, W., and Becker, M. J. "Ethics of E-Voting: An Essay on Requirements and Values in Internet Elections," in P. Brey, F. Grodzinsky, and L. Introna (eds.), Ethics of New Information Technology: Proceedings of the Sixth International Conference of Computer Ethics: Philosophical Enquiry (CEPE 2005), Center for Telematics and Information Technology, Enschede, The Netherlands, July 17-19, 2005, pp. 307-318.

Schot, J., and Rip, A. "The Past and Future of Constructive Technology Assessment," Technological Forecasting and Social Change (54), 1997, pp. 251-268.

Smits, M. "Monster Ethics: A Pragmatist Approach to Risk Controversies on New Technology," paper presented at the Research in Ethics and Engineering Conference, University of Delft, The Netherlands, April 25-27, 2002a.

Smits, M. Monsterbezwering: de culturele domesticatie van nieuwe technologie, Amsterdam: Boom, 2002b.

Verbeek, P-P. What Things Do: Philosophical Reflections on Technology, Agency, and Design, University Park, PA: Pennsylvania State University Press, 2005.

Warschauer, M. Technology and Social Inclusion: Rethinking the Digital Divide, Cambridge, MA: MIT Press, 2004.

Weber, M., Hoogma, R., Lane, B., and Schot, J. Experimenting with Sustainable Transport Innovations: A Workbook for Strategic Niche Management, Enschede, The Netherlands: University of Twente, 1999.

Weinstein, L. "Risks of Internet Voting," Communications of the ACM (43:6), 2000, p. 128.

Winner, L. Autonomous Technology: Technics-Out-of-Control as a Theme in Political Thought, Cambridge, MA: MIT Press, 1977.

\section{About the Author}

Wolter Pieters is a junior researcher in the Security of Systems group at the Radboud University Nijmegen. He studied computer science and philosophy of science, technology, and society at the University of Twente. The topic of his current research is the conditions under which Internet voting can be acceptable, both from technical and social perspectives. He can be reached atwolterp@cs.ru.nl. 